\title{
Deconfusion of the Child ego state - An examination of the main contributions and how redecision adds to the literature
}

\author{
(C) 2021 Tony White
}

\begin{abstract}
This paper examines some of the main writings about deconfusion of the Child in the transactional analysis literature. It seeks to show how each approach defines the goals of deconfusion and the methods by which deconfusion is obtained. In doing this it clarifies the three methods which Berne proposed could be used for such deconfusion. It also attempts to show how redecision therapy adds to the literature on the topic, which to the writer's knowledge has not been done before.
\end{abstract}

\section{Key words}

deconfusion, redecision therapy, psychoanalysis, empathic transactions, therapeutic relationship, regression, feelings, emotions, interpretation, decontamination.

\section{Introduction}

Eric Berne (1961) first mentioned the idea of deconfusion of the Child ego state quite early in his writings. Since that time the concept of deconfusion of the Child has been used by a number of others over a long period. Indeed Widdowson (2010) refers to deconfusion as one of the 'backbones' or central tasks of transactional analysis (TA) therapy. The different writings have unfortunately and ironically led to considerable confusion about this idea of deconfusion. This article seeks to show some of the main alternate ways the concept has been used so as to give an overall understanding of how deconfusion of the Child can occur. It is by no means a complete review of the literature on deconfusion of the Child. Instead it seeks to identify some of the main contributors to this topic in the literature and the themes of what they are saying.

The idea of deconfusion of the Child was been embraced in particular by the relational TA approach and particularly by Hargaden and Sills (2001). However this has not happened with redecision therapy. Goulding and Goulding said almost nothing about this. There is only one very brief mention by Robert Goulding (1981) where he says that true change occurs when the Child is deconfused. This paper seeks to remedy this omission and examine the significant ways the redecision approach adds to the literature on deconfusion of the Child.

\section{Berne's view of deconfusion}

In his description of Mr. Segundo's case, Berne (1961) states that through structural analysis the Adult ego state becomes dominant in the personality and then a pragmatic cure has been obtained. In a later book (Berne 1972) he writes "In transactional analysis, the Adult is enlisted as an ally as soon as possible and proves its worth." (p.378). Once done then one has the option to use psychoanalysis and/or regression analysis to deconfuse the Child ego state. This may be used after the transactional analysis treatment or not.

In Berne (1966) he reiterates this process in his discussion of the eight types of therapeutic operations and their therapeutic goals. The first six - interrogation, specification, confrontation, explanation, illustration and confirmation - are about strengthening the Adult through decontamination. The seventh - interpretation - is about using psychoanalytic interpretation to deconfuse the Child. The eighth - crystallisation - is the final stage of pure transactional analysis and is not designed to deconfuse the Child. In the literature there is some confusion on this point as some writers do include crystallisation as a technique for deconfusion of the Child. This final stage of treatment can occur whether there has been deconfusion of the Child via interpretation or not. This stage is where the therapist is assessing and preparing the client to terminate therapy. This is where the final decision to get well is made by the client and if there is crystallisation then as Berne (1966) puts it, the "...son announces at the age of forty that he is finally leaving home to get married." (p.246). 
Back in 1961, Berne proposed that one way to do deconfusion of the Child is by psychoanalytic interpretation and then suggests a second way to deconfuse the Child using the technique of regression analysis. Erskine (2003) has also raised the idea of Berne proposing regression analysis as a means to deconfusion. Upon closer examination we find significant evidence that Berne did actually use regression analysis as a way to deconfuse the Child ego state.

Firstly he reports that psychoanalytic cure means deconfusing the Child with a largely decontaminated Adult as an ally. He goes on to say, "In hypnosis, the mother and the governess are metaphorically sent out of the room and later the therapist tells them what the Child said. In psychoanalysis the Child speaks in their presence and they hear it first hand. Regression analysis, which will be discussed later, retains the same advantage, while at the same time appealing more directly to the Child." (p.173). Furthermore Berne later mentions the work of Franz Alexander who describes the "corrective emotional experience" and then says, "In structural terms, Alexander's principle is a psychoanalytic one, since the aim is to deconfuse the Child," (p.174).

To further clarify the deconfusing effect on the Child by using regression analysis as a corrective emotional experience, Berne quotes the report by a patient called Iris: "You know, since yesterday l've felt clearer than I have for years. It's as though I were emerging out of a fog. Recognizing the Child is one thing, but actually experiencing it is another. It's frightening. Knowing that it's my Child doesn't make it any more comfortable for me, but it does relieve me: at least I know where those feelings are coming from" (p.249-250). This quote clearly show that her Child ego state is now less confused.

Regression analysis as described by Berne is a technique that allows for the cathartic expression of the Child ego state's thoughts and feelings. There is an emotional expression from the Child where an abreaction and working through can take place. "Phenomenologically, the Child appears as a discrete, integrated ego state."(p.247) and "Here it is not the Adult talking about the Child, but the Child talking itself."(p.248). In regression analysis the Child is given the opportunity to have the cathartic expression of emotions with the goal to deconfuse that Child ego state. This allows the previously buried Child ego state to be .."permanently at the disposal of the patient and the therapist for detailed examination."(p.248). That examination allows for interpretations to take place and in addition it allows for an abreaction and working through of the emotions.

Moving on to 1966 again, it is interesting to see Berne (1966) also say, "Regression analysis, in which the therapist, in to order activate and decontaminate the patient's Child, cathects his own Child ego state" (p.314). All along Berne has spoken about the decontamination of the Adult ego state and not the Child ego state. He is very clear that it is the Adult ego state that is decontaminated and not the Child ego state and that after decontamination has taken place then the therapist strengthens the boundary between the Adult and the Child. Decontamination takes place in the Adult and deconfusion takes place in the Child. One could only assume that Berne used the wrong word here and meant to say, 'regression analysis is used to activate and deconfuse the patient's Child'.

In summary Berne proposes the three following ways for deconfusion of the Child:

- orthodox psychoanalysis using the therapeutic operation of interpretation

- interpretation through regression analysis

- $\quad$ cathartic expression of emotions which permits the working through of the Child's thoughts and feelings.

\section{Subsequent contributions to the literature}

The following material is summarised in Table 1 showing methods and goals, and Figure 1 showing a flowchart of the development of theory.

Erskine (1973) writes about the six stages of treatment. In the second stage he talks about the deconfusion of the Child. He proposes that this involves the client gaining awareness of feelings. This is achieved by the therapist offering protection and permission to the client.

This is a significant departure from what Eric Berne proposed. It has nothing to do with orthodox psychoanalysis and interpretation as a stage of treatment after the transactional analysis treatment and decontamination have been done. However his proposal of deconfusion as a way to gain awareness of feelings is similar to Berne's idea of regression analysis and deconfusion about feelings by 'working them through'.

Osnes (1974) says that deconfusion of the Child can be achieved by giving the client an experience of nurturing and warm caring. This will then replace the traumatic hurt that was experienced as a result of the original parenting. Osnes is using the concept of deconfusion of the Child in a very different way to Berne. He is the first to present the idea of a warm empathic therapeutic relationship as a means for deconfusion of the Child.

Woollams and Brown (1978) discuss stages of treatment and cite that stage four is deconfusion of the Child. The goal of this stage is to deconfuse the client's 
Berne 1961 \& 1966

Deconfusion of the Child (Two methods)

1. Psychoanalytic interpretation

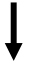

No further development

Osnes 1974

Therapeutic relationship

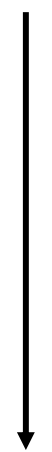

Clark 1991

Empathic transactions

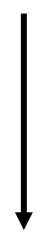

Hargaden \& Sills 2001

Empathic transactions

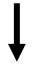

Widdowson 2010

Psychodynamic therapy

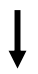

Cornell et al 2016

Reparative relationship

\section{Regression analysis}

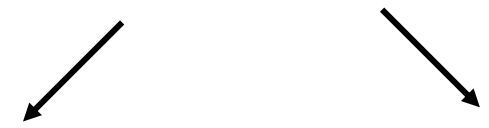

Interpretation

Cathartic working through of emotions

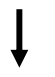

Erskine 1973

Awareness of feelings

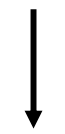

Woollams \& Brown 1978

Interpretation of script beliefs

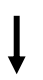

Goulding 1979

Interpretation of

unconscious material
Woollams \& Brown 1978

Expression of feeling

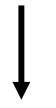

Goulding 1979

Gestalt techniques to express feelings

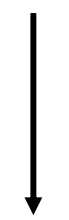

Clarkson 1992

Cathartic expression of feelings

Figure 1: Deconfusion of Child: Development of Theory 


\begin{tabular}{|c|c|c|}
\hline Theorist & Method of deconfusion & Goal of deconfusion \\
\hline Berne -1961 \& 1966 & $\begin{array}{l}\text { 1. Psychoanalytic interpretation } \\
\text { 2. Regression analysis interpretation } \\
\text { 3. Regression analysis catharsis } \\
\text { 4. Deconfusion is a long-term analytical } \\
\text { process. }\end{array}$ & $\begin{array}{l}\text { 1. Understanding of the previously } \\
\text { buried Child ego state material } \\
2 \text {. Working through of emotions for a } \\
\text { better understanding of feelings }\end{array}$ \\
\hline Erskine 1973 & Offering protection and permission & Awareness of feelings \\
\hline Osnes 1974 & $\begin{array}{l}\text { New relationship experience of warmth } \\
\text { and caring }\end{array}$ & Replace original traumatic hurt \\
\hline Woollams \& Brown 1978 & $\begin{array}{l}\text { Techniques and questioning to identify } \\
\text { script material. Deconfusion can be } \\
\text { achieved in a single piece of work or } \\
\text { can occur over a long period of time. }\end{array}$ & $\begin{array}{l}\text { 1. Get in touch with unmet needs and } \\
\text { feelings } \\
\text { 2. To develop internal sense of safety } \\
\text { 3. Get client ready for redecision }\end{array}$ \\
\hline Goulding 1979 & $\begin{array}{l}\text { 1. Interpretation of unconscious } \\
\text { material through interrogation and } \\
\text { regression analysis } \\
2 \text {. Working through emotions by } \\
\text { regression analysis }\end{array}$ & $\begin{array}{l}\text { 1. To become aware of unconscious } \\
\text { script material in the Child developed } \\
\text { from early experiences } \\
\text { 2. To discover what they are feeling } \\
\text { and who or what they are feeling it } \\
\text { about } \\
\text { 3. Get the client ready for a redecision }\end{array}$ \\
\hline Clark 1991 & $\begin{array}{l}\text { Creating an empathic bond through the } \\
\text { use of empathic transactions }\end{array}$ & $\begin{array}{l}\text { To increase the client's sense of } \\
\text { legitimacy and safeness about its } \\
\text { needs and emotions }\end{array}$ \\
\hline Clarkson 1992 & $\begin{array}{l}\text { The cathartic expression of emotions } \\
\text { by the Child }\end{array}$ & $\begin{array}{l}\text { To understand and clarify the thoughts, } \\
\text { feelings and belief of the Child. }\end{array}$ \\
\hline $\begin{array}{l}\text { Hargaden \& Sills } 2001 \& \\
2002\end{array}$ & $\begin{array}{l}\text { By facilitating the unconscious } \\
\text { processes of the client to enter into the } \\
\text { transference relationship, this is then } \\
\text { analysed along with the therapist's } \\
\text { counter transference reactions. }\end{array}$ & $\begin{array}{l}\text { To bring the dormant, archaic and } \\
\text { conflicted unconscious parts of self into } \\
\text { the conscious }\end{array}$ \\
\hline Widdowson 2010 & $\begin{array}{l}\text { By the use of empathic transactions in } \\
\text { the transference relationship. }\end{array}$ & $\begin{array}{l}\text { To resolve early childhood experiences } \\
\text { and the feelings associated with those. }\end{array}$ \\
\hline Cornell et al 2016 & $\begin{array}{l}\text { The client 'uses' the therapist to relive } \\
\text { old relationships in the therapeutic } \\
\text { relationship. }\end{array}$ & $\begin{array}{l}\text { To transform old feelings into new } \\
\text { manageable ones. }\end{array}$ \\
\hline
\end{tabular}

Table 1: Deconfusion of Child: Method and Goal

Child by " helping her get in touch with and express unmet needs and feelings and to help her develop an internal sense of safety sufficient to make a redecision." (p.262). They suggest using techniques and asking questions which will bring unconscious information to the foreground for the client. Previously unconscious script beliefs are brought into awareness. It is the preparation of the Child ego state for a redecision to occur. That preparation is done by assisting the client to get into touch with and express their unmet needs and feelings. This is similar to Berne's idea of regression analysis. Also there is agreement with Erskine about deconfusion being used to clarify and understand feelings. Finally there is a similarity to Berne in terms of questioning the client to seek out the unconscious beliefs and thoughts. 
Clark (1991) says deconfusion is necessary for traumatically fixated Child ego states. She also states that a child needs to be deconfused about the legitimacy and safeness of its needs and emotions. Deconfusion is achieved by creating an empathic bond and through the use of empathic transactions. Through the therapeutic bond the client starts to believe their emotional states and needs are understood by the therapist and this is what she calls deconfusion. She says that once the empathic bond is established then the early ego states are available for therapeutic work and deconfusion. This bond must first be established because if therapy proceeds without such a bond occurring then the archaic child needs will go underground because the Child will experience being rebuffed and then become inaccessible for deconfusion.

As White (2021) has shown, Clark's view is indicative of catastrophizing beliefs systems about the Child ego state of the client. It is a significant underestimation of the resilience of the average client, who can handle many therapeutic techniques such as decontamination, like Berne would do before a deep therapeutic bond has been formed. The Child ego state of the average client will not feel rebuffed or go into hiding as a result of them.

This is also a significant departure from what Berne describes as deconfusion. As Osnes proposed, we have the view that deconfusion of the Child is achieved by using the therapeutic relationship. Berne never made any mention of this. Clark mentions nothing about the use of psychoanalytic interpretation with the Child and says in her view the confusion is about the safeness and legitimacy of needs and emotional states.

Clarkson (1992) is of the view that deconfusion results from the thoughts, feelings and beliefs of the child being given expression in order to be understood, clarified and given their rightful place. She clearly equates the cathartic expression of emotions with deconfusion. This has some similarities with Berne's idea of regression analysis for deconfusion using abreaction and the working through of emotions but the idea of using the expressions of the Child ego state for detailed examination for psychoanalytic interpretation is never mentioned

Hargaden and Sills $(2001,2002)$ follow on directly from the proposal by Clark on the importance and role of the empathic relationship for deconfusion of the Child ego state. For example, they note that the therapist must be emotionally available to let parts of the client impact on them as this allows the client to integrate split-off parts of self. Also, the therapist must pick up on the unmet relational needs and then respond appropriately. This is the process for facilitating deconfusion in the Child.
They clearly suggest an interpretative role for deconfusion of the Child which is consistent with Berne's original idea. One uses the analysis of the transference relationship and the transference neurosis to bring the unconscious archaic and conflicted parts of self into consciousness. The therapist facilitates the client to bring their own Child ego state experiences, feelings and sensations into the therapeutic relationship. The therapist remains aware of their own countertransference reactions to those and then an analysis of this allows for the unconscious material of the client to arise into the consciousness of the client.

Hargaden and Sills highlight the fact that Berne said in treatment that decontamination comes first and deconfusion follows. They suggest that this is an artificial split between decontamination and deconfusion and that deconfusion using the empathic relationship occurs right from the beginning of treatment. In one sense they have to conclude this as their approach is wholly based on using the transference to facilitate cure in the client, so the therapeutic alliance is the central focus of treatment right from the beginning. If deconfusion is done via the therapeutic relationship, ergo, deconfusion must occur from the beginning of treatment; there cannot be a period of time whilst decontamination is done before the therapeutic relationship can be used to deconfuse the Child ego state.

As further evidence for this, they use a similar rationale to Clark's (1991). You cannot first do decontamination before a strong therapeutic alliance has been established because the client will feel overwhelmed and attacked and therefore either leave therapy or simply adapt to the therapist. As mentioned above, in my view this represents catastrophising beliefs and the average client is far more robust than that and can easily handle decontamination techniques before the empathic relationship is established to the degree they say it has to be. Eric Berne successfully did that for fifteen years and Goulding and Goulding did it for twenty years. As mentioned before about Clark, this is a significant departure from what Berne originally proposed as to the nature of deconfusion. He never discussed empathic transactions and the transference relationship as a method, or that it even plays any role in deconfusion of the Child.

Widdowson (2010) makes some good clarifying comments about how deconfusion and decontamination are separate and how they are connected. "Structurally speaking, decontamination is a process involving the Adult ego state, and deconfusion is a process involving the Child ego state." (p.273). He proposes that deconfusion would be part of the process that occurs in psychodynamic therapy especially in the area of transference analysis. 
He supports the view that empathic transactions in the therapeutic relationship are what result in deconfusion. As to the goal of deconfusion, he provides an interesting new perspective when he talks about deconfusion in relation to the formation of script beliefs. The young child has early traumatic experiences and the resulting feelings get connected to these experiences. Deconfusion is aimed at resolving those early experiences and the feelings connected to them.

Cornell, de Graaf, Newton and Thunnissen (2016) see deconfusion as disentangling the Child ego state from emotional beliefs and forces from the past, related to early needs that have been insufficiently met or damaged. The client is deconfused by using a reparative relationship with the therapist where the client 'uses' the therapist to experience and process the old rejecting feelings and the therapist helps the client transform these into a manageable form within the client. "The therapist works with her (own) and the client's images, fantasies and feelings which are called up during the transference relationship." (p.80). Again, a significant departure from what Berne said about deconfusion but following the theme from Clark, and Hargaden and Sills, in using the transference relationship as a means to deconfuse the Child.

\section{Redecision therapy and deconfusion of the Child}

Upon studying deconfusion in depth it became apparent just how much redecision work is actually deconfusion of the Child. Like Berne, Goulding and Goulding (1979) had an aversion to longer-term psychoanalytic types of therapy. Indeed, this could explain Berne's ambivalence to deconfusion of the Child that is noted by Hargaden and Sills (2001). "However, he also revealed an ambivalent attitude toward working with the dynamic Child, sometimes referring rather dismissively to the 'luxury' (p.149) of analysing the Child and at other times suggesting deconfusion as a phase of treatment". (p.55).

I agree with their observation about the ambivalence of Berne on this topic and it is understandable. As Hostie (1984) notes, Berne broke away from psychoanalysis in about 1956 after another rejection on his psychoanalysis examinations. At that point he set about developing transactional analysis as a shortterm solution-focused therapy. Many times he talked about curing people first and analysing them later. White (2021) explains how Berne, throughout his entire writings, raised the question of 'making progress versus cure'. He repeatedly questioned the validity of using longer-term analytic-type therapies like psychoanalysis which tended to just 'make progress'. For him to suggest using orthodox psychoanalysis as a way to deconfuse the Child is precisely what he was beginning to move away from at that time in 1961.
Thus, he had ambivalent views on the use of psychoanalysis for deconfusion because he was evolving a short-term solution-focused psychotherapy at that very same time.

Goulding and Goulding (1979) did however bring gestalt therapy into use with transactional analysis and thus we get deconfusion of the Child in a similar way to the regression analysis that was discussed by Berne. As stated above this allows for deconfusion by the second and third options: interpretation through interrogation and regression analysis; and working through of emotions by regression analysis.

When connecting and working with the client, Goulding and Goulding would use the therapeutic operation of interrogation where the therapist gets to know the client in relation to the topic that the client presents. This allows one to discover the Child beliefs and Parent prejudices. McNeel (1975) provides examples of how Goulding and Goulding would use interrogation to get to interpretation with the client. They brought to the attention of clients ways by which they were sabotaging self. For example, they would confront incongruities where the person's body language was incongruent with what they were saying. The verbal is the conscious speaking and the non-verbal (body language) is the unconscious of the client speaking. Thus they brought the unconscious of the client into the conscious. They would also ask clients to own their projections and would identify to the client when they were presented with a Parent ego state contract. McNeel also reports how Goulding and Goulding would separate myth from reality, "Many people carry with them a mythical view of reality in which they misperceive facts." (Goulding and Goulding, 1979, p.122). Goulding and Goulding would bring it to the client's attention when they were thinking in such magical ways and hence the unconscious would be brought into the conscious. The Child is being deconfused in this way.

Redecision therapy also uses a version of regression analysis, as Berne originally proposed, for the cathartic working through of emotions as a means to deconfuse the Child. This allows the client to realise what they are actually feeling and who or what they are feeling it about. This second option is similar to what Clarkson (1992) suggests as deconfusion of the Child through catharsis; Erskine (1973) also talks of deconfusion being an awareness of feelings. Through gestalt techniques the client can regress and often this will include the cathartic expression of emotions. Of course all this prepares the client for making a redecision, which can be seen as the third goal of redecision and concurs with what Woollams and Brown (1978) stated.

The two case examples below provide insight into common dialogue one would find in redecision therapy 
at the interrogation and information gathering stage when the client is regressed.

\section{Case example 1}

Ronan: "I have a feeling of anxiety in my body." (feeling scared)

Therapist: "What does the body language say?"

Ronan: "I'm scared and leave me alone."

Through regression the client's Child ego state now understands his fear and his desire to be left alone.

Further discussion occurs about the feelings and thoughts associated with those feelings which leads to further discovery:

Ronan: "I am still hoping for love from my parents." "I feel anger about the past." (feeling angry)

Therapist: "Be that anger and talk."

Ronan: "Yes I am angry at them and how they withheld love. Now I also feel sadness about the past with them."

As Clarkson (1992) says, with the expression of emotion the Child can be deconfused as the feelings and beliefs are understood and clarified. Ronan has clarified his anxiety, anger and sadness as well as his hope for love from the parents.

\section{Case example 2}

Olive: "I have envy for my sister. My parents always treat her better than me, and they talk about her talents to others and never about me."

Therapist: "What do you feel now?"

Olive: "I am angry at my parents. I want them to stop it." (feeling anger)

Therapist: "Say more."

Olive: "I am also angry at my sister".

A few minutes later:

Olive: "And I am sad at my sister as she has many problems."

Through regression and catharsis Olive clarified and expressed her feelings of anger at the parents, anger at the sister and also sadness about the sister. Olive is now more aware about what she feels and who she feels it about.

\section{Summary}

As mentioned previously, Table 1 displays a summary of some of the main contributors to the concept of deconfusion of the Child, showing the method of deconfusion and the goal of deconfusion.

Figure 1 shows a flowchart linking the four different strands of understanding for deconfusion that have developed so far. Berne's suggested use of psychoanalytic interpretation has had no further development whereas his idea of deconfusion with regression analysis has had many authors expand and further discuss those ideas. In 1974 a new strand began that was not directly discussed by Berne, using the therapeutic relationship to deconfuse the Child; there have been a number of further discussants on that topic.

\section{Conclusion}

It is indeed unfortunate that we only got thirteen years of writing on transactional analysis by Eric Berne before his premature death. Another ten years would have been good to see where his thinking evolved to. At the beginning of the thirteen years he was still heavily influenced by psychoanalytic thinking and as a result deconfusion of the Child was viewed in that way, at least partly. As he moved away from psychoanalysis towards transactional analysis in his thinking, he became ambivalent about the deconfusion of the Child ego state by using psychoanalysis. The summaries found in Table 1 and Figure 1 show the developments over time of the idea of deconfusion of the Child ego state. Further developments will certainly occur in this area and many others. One of the reasons transactional analysis has endured for so long is that it allows for new developments in theory and practice.

Tony White is a Teaching \& Supervising Transactional Analyst (Psychotherapy), a psychologist and psychotherapist, and author of numerous articles and several books. He can be contacted on agbw@bigpond.com.

\section{References}

Berne, E. (1961). Transactional Analysis in

Psychotherapy. Ballantine Books.

Berne, E. (1966). Principles of Group Treatment. Oxford University Press.

Berne, E. (1972). What Do You Say After You Say Hello? Bantam Books.

Clark, B. D. (1991). Empathic Transactions in the Deconfusion of Child Ego States. Transactional Analysis Journal, 21(2), 92-98. https://doi.org/10.1177/036215379102100204

Clarkson, P. (1992). Transactional Analysis

Psychotherapy. Routledge. https://doi.org/10.4324/9780203753996

Cornell, W.F., De Graaf, A., Newton, T., \& Thunnissen, M. (2016). Into TA: A Comprehensive Textbook on Transactional Analysis. Karnac.

Erskine, R. (1973). Six stages of treatment. Transactional Analysis Bulletin, 3(3), 17-18. https://doi.org/10.1177/036215377300300304 
Erskine, R. (2003). Introjection, Psychic Presence and Parent Ego States: considerations for psychotherapy. In Sills, C. \& Hargaden, H. (Eds). Ego States. Worth Publishing. 81-108.

Goulding, R., \& Goulding, M. (1979). Changing lives through redecision therapy. Brunner/Mazel Publishers.

Goulding, R. L. (1981). Challenging the Faith. Transactional Analysis Journal, 11(1), 50-53. https://doi.org/10.1177/036215378101100111

Hargaden, H., \& Sills, C. (2001). Deconfusion of the Child Ego State: A Relational Perspective. Transactional Analysis Journal, 31(1), 55-70. https://doi.org/10.1177/036215370103100107

Hargaden, H., \& Sills, C. (2002). Transactional Analysis: A Relational Perspective. Routledge.

Hostie, R. (1984). Eric Berne in search of ego states. In Stern, E. (Ed). TA The State of the Art. Foris Publications. 11-29.
McNeel, J. R. (1975). Redecisions in Psychotherapy: A Study of the Effects of an Intensive Weekend Group Workshop (Doctoral dissertation). The California School of Professional Psychology.

Osnes, R. E. (1974). Spot reparenting. Transactional Analysis Bulletin, 4(3), 40-46. https://doi.org/10.1177/036215377400400308

Tilney, T. (1998). Dictionary of Transactional Analysis. Whurr Publishers.

White, T. (2021). Redecision Therapy Today: A Redecision Relational Approach to Transactional Analysis. TA Books.

Widdowson, M. (2010). Transactional Analysis: 100 Key points \& Techniques. Routledge.

Woollams, S., \& Brown, M. (1978). Transactional Analysis. Huron Valley Institute Press. 